Original Research Paper

\title{
Looking Inside and Outside the System: Examining the Factors Influencing Distance Learners Satisfaction in Learning Management System
}

\author{
${ }^{1}$ Ibrahim Almarashdeh, ${ }^{1}$ Mutasem Khalil Alsmadi, ${ }^{2}$ Ghaith Jaradat, \\ ${ }^{3}$ Ahmad Althunibat, ${ }^{4}$ Sami Abdullah Albahussain, ${ }^{5}$ Yousef Qawqzeh, \\ ${ }^{1}$ Usama A Badawi, ${ }^{1,6}$ Tamer Farag and ${ }^{1,6}$ Kamal Eldin Eldaw \\ ${ }^{1}$ College of Applied Studies and Community Service, \\ Imam Abdurrahman Bin Faisal University, Al-Dammam, Saudi Arabia \\ ${ }^{2}$ Department of Software Engineering, Faculty of Science and Information Technology, \\ Al-Zaytoonah University of Jordan, Amman, Jordan \\ ${ }^{3}$ Department of Computer Science, Faculty of Information Technology, \\ Jerash University, 26150-311 Jerash, Jordan \\ ${ }^{4}$ Department of Business Administration, College of Business Administration, \\ Imam Abdurrahman Bin Faisal University, Al-Dammam, Saudi Arabia \\ ${ }^{5}$ College of Science-Zulfi, Majmaah University, KSA \\ ${ }^{6}$ Department of Mathematics, Faculty of Science, Cairo University, Egypt
}

Article history

Received: 23-02-2018

Revised: 22-03-2018

Accepted: 4-04-2018

Corresponding Author: Mutasem Khalil Alsmadi College of Applied Studies and Community Service, Imam Abdurrahman Bin Faisal University, Al-Dammam, Saudi Arabia

Email: mksalsmadi@gmail.com

\begin{abstract}
In the last few years, the use of educational technology, particularly the concept of Learning Management System (LMS), has increased rapidly. With this fast development, the question arises as how to manage the LMS to obtain success and efficiency in online courses. One of the important factors that have received many citations in literature studies (and has a special position in information system research) is the user satisfaction. It is a crucial factor that can predict the success or failure of any LMS. In relation, this research examined the success factors that affect the user satisfaction and outcomes of LMS. This paper discusses the conceptual User Satisfaction Evaluation Model (USEM) employed to measures LMS success. In particular, it seeks to examine "the relationship between: Service quality, system quality, ease of use, perceived usefulness, information quality and students satisfaction, as well as to measure the outcomes of the LMS." Results from the data analysis indicate that all proposed factors have a positive effect on student satisfaction. The result also concludes that a higher rate of user satisfaction will lead to greater benefits for the students.
\end{abstract}

Keywords: Distance Learning, Learning Management System, User Satisfactions, Information Quality

\section{Introduction}

In the higher education, the use of learning management system in distance learning or online courses is widespread. Incorporation of LMS into teaching and learning practices was increased in the sectors of higher education (Gautreau,

2011). The successful implementation of LMS can be seen by the utilization of LMS by the end users (Rafi et al., 2015). End user satisfaction nowadays is an essential topic because of the increasing number of institutions that utilize LMS in online courses which resulted in a need for an evaluation method to measure the effectiveness of LMS. Every organization aims to satisfy their customers or users, especially the universities. Using LMS in delivering courses is considered as an important goal for the universities to manage and assess the work of their students. The concept of user satisfaction is known as the extent to which the stakeholders believe that the technology they are using has met their needs (Ives et al., 1983). It is considered as the main variable that shows the different in success in the 
marketplace (Gitman and McDaniel, 2008). Furthermore, analysing user satisfaction is beneficial for improvement of the product (Li et al., 2010).

A number of researchers believe that if the Information System (IS) meets the needs of the students, the students' satisfaction will increase (Cyert and March, 1992). Conversely, if the Information System (IS) does not provide the required information, that will lead to dissatisfaction among users (Bergersen, 2004). Moreover, specifically relating to LMS, most previous studies evaluated only one type of LMS; researchers recommended to conduct further researches on multiple LMS programs to gain more generalized and valid results (Hilmi et al., 2012; Almarashdeh et al., 2013; Khalid et al., 2015). Hence, a comparative analysis of students' perceptions in using LMS is needed, as several researchers have recommended that more research should be conducted in order to better understand the distance learning courses and its impact on students' satisfaction (Sher, 2009).

The target of this study is the biggest shareholders of the educational system, the students. The level of students' satisfaction with the learning system needs to be investigated, in the other hand the satisfaction level depends on several factors that affects the users such as what service does students' needs? Or what the LMS provides? Is what students needs available in the LMS? Is the LMS user friendly or complicated? Therefore, this study aims to examine the factors influencing students' satisfaction with learning management systems in distance learning courses.

\section{Related Work}

Until today, there has been limited complete evaluation model to assess the effectiveness of LMS. The latest published information in user satisfaction considered various factors such as: The content currency, content completeness, ease of access, ease of navigation, as well as course staff responsiveness as being critical success factors of student satisfaction recorded when using LMS (Naveh et al., 2012; Almarashdeh, 2016). The authors did not take into account the perceived usefulness, system quality and service quality as the main factors that might affect a student's level of satisfaction. On the other hand, other researchers claimed that student satisfaction is influenced by frequency of use and service quality (Green et al., 2012). Another study claimed that accessibility problems, poor technical support and less familiarity with technology might frustrate the students' satisfaction and cause high levels of frustration with online courses (Naaj et al., 2012). The loyalty of user to service enterprises is directly affected by User satisfaction. In a service context, quality and value are proposed to be satisfaction antecedents; satisfaction mediates the influence of quality and value on loyalty (Llewellyn, 2011; Almarashdeh et al., 2010).

A more integrated view of IS and a more formulated IS success model was initiated by DeLone and McLean (1992), in which information quality and system quality are depicted as influencing factors for IS use and user satisfaction. A study of IS success dimensions suggests that technology qualities such as system, service and information quality have influenced perceived usefulness, user satisfaction and system usage (Sabherwal et al., 2006). Furthermore, a model developed by Wixom and Todd (2005) (based on user satisfaction and technology acceptance literature) was tested on a sample of 465 participants from seven organizations while considering their utilization of software for data warehousing. The finding of the study showed a significant effect of information and system quality on perceived ease of use and perceived usefulness. In addition, the study suggested more investigation to be carried out on the effects of the information technology design and development as a predictor to usefulness, ease of use and related variables (Wixom and Todd, 2005). In LMS, a many researchers choose different variables to expect satisfaction of user in terms of: Culture influence, capacity of use and technology adoption.

A recent study in user satisfaction of LMS used independent variables such as: Course discipline, course size, course year, staff size, instructor status, content posted on the online course and support of surveys and forums in online courses to predict student satisfaction (Naveh et al., 2010). Furthermore, recent researchers on the learning management system perception did not indicate the significance of system abilities; like: functionality and availability of the learning management system; the quality of service; like: A follow up service, empathy and help desk, in addition to quality of information that is important for students for obtaining valued information from the learning management system by guaranteeing: Accuracy of information, relevancy, legibility, reliability, availability, consistency, timeliness and completeness. These issues are important for the distance learning programs to be successful. The factors of technology can give sureness to students for online studying if the learning management system has suitable study environment, having ease of use and having better features will facilitate the learning process.

\section{Method of this Research}

The research model and hypotheses are outlined in this section. 


\section{Research Model}

We built the proposed model based the information system success model and Technology Acceptance Model (TAM) (Almarashdeh et al., 2010a; 2011a). Perceived ease of use and usefulness has been used as the mean variable in technology acceptance. However, the TAM did not measure overall service and information quality even though it has a strong effect on behaviour intention based on literature studies (Wixom and Todd, 2005). The IS success model did not provide a sufficiently clear intention regarding usefulness and ease of use of the new technology, even though prior studies found significant results (such as of usefulness and ease of use regarding user acceptance of new technology and user satisfaction) (Almarashdeh et al., 2010b; Rai et al., 2002).

This work shows the importance of the learning management system success measuring based on the perspective of IS. Particularly, the preceding factors are collected from the persistent development and improvement in, developing, designing and delivering the essential facilities for distance learning users. Figure 1 describes the characteristic of the User Satisfaction Evaluation Model (USEM) that is proposed in this research.

\section{Research Hypothesis and Model Constructs}

According to (Chen et al., 2009), educational technology quality is an important factor influencing usage and satisfaction of the learning system. Further, they have suggested further studies to be conducted in order to explore the impact of educational technology quality on learners' behavior. User satisfaction is seen to be influenced by different factors such as: User expectation; attitude and system output; perceived usefulness and ease of use; task difficulty and system type. Moreover, system effort and effectiveness influence user satisfaction (AlMaskari and Sanderson, 2010). Also, technological issues (System quality) have a major impact on user satisfaction (Almarashdeh and Alsmadi, 2017; MOHE, 2006). Some other researchers suggested that perceived ease of use, perceived service quality and perceived usefulness affect user satisfaction (Adewumi, 2013; Almarashdeh et al., 2010c). At the same time, others used quality dimensions such as: service quality, system quality and information quality to measure user satisfaction (Delone and McLean, 2003). On the other hand, developers were concerned with: content accuracy, ease of use, format and timeliness, speed and efficiency, language and learnability, documentation, motivation and job satisfaction, as well as aesthetics and enjoyment by which to measure user satisfaction (CSU, 2005). Although satisfaction of user was highly affected by many factors such as perceived benefit and expectations, but the ease of use hasn't been considered as one of the most significant factors (Adam, 2000). In different contexts, many researchers utilized diverse factors to measure user satisfaction of the LMS. These included: ease of use, content and systems integration, ease of ownership and support and vendor service (Ibrahim and Silong, 1997).

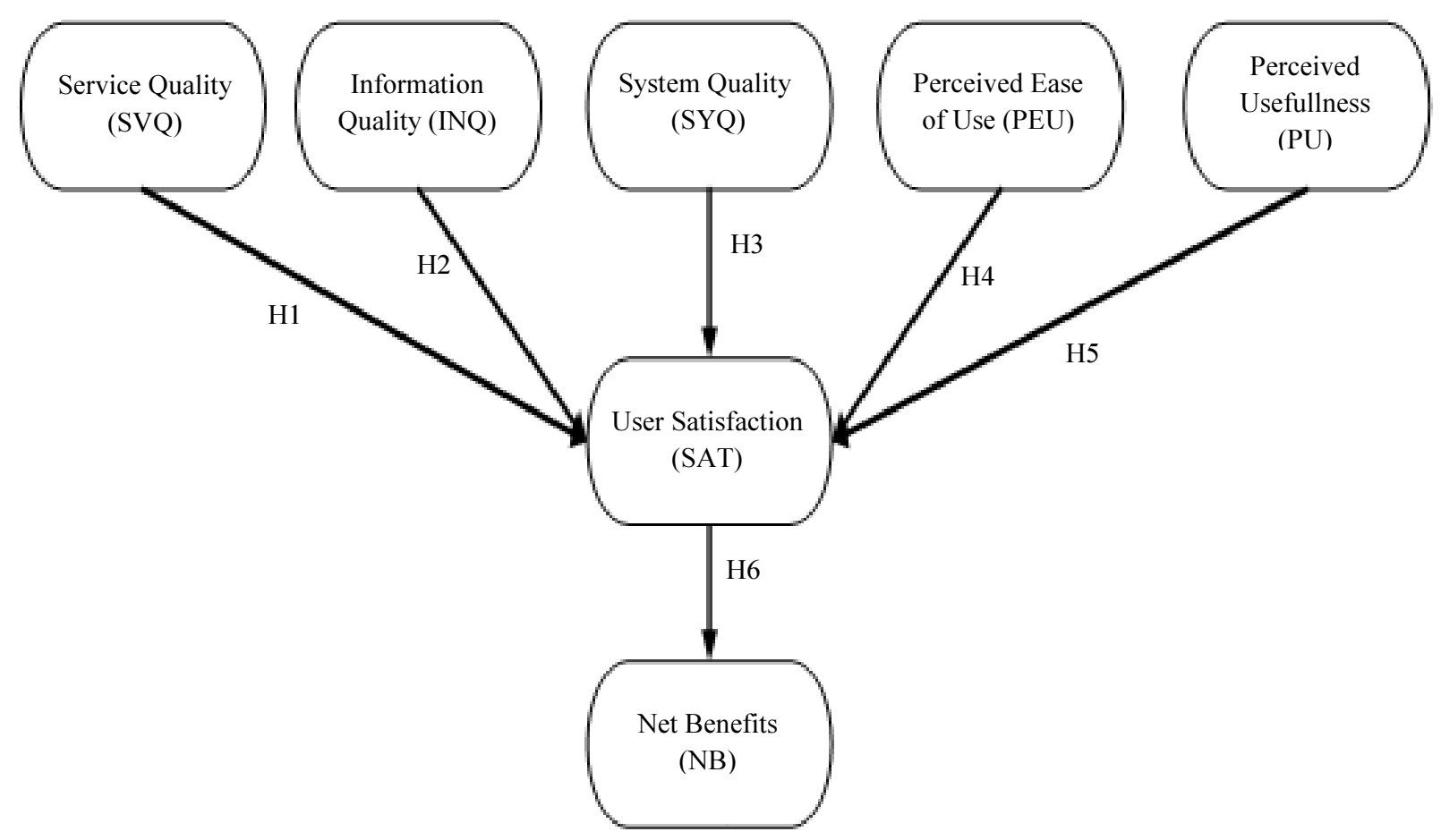

Fig. 1: The USEM 
In this study, we used: Service quality, system quality and information quality, perceived ease of use and perceived usefulness as the main measurements of student satisfaction when using LMS in distance learning courses. Figure 1 above represents the theoretical model for this study. The model indicates the relationship between: Perceived ease of use, perceived usefulness, system quality, service quality and quality of information and student satisfaction. The model that is proposed in this work is called User Satisfaction Evaluation Model. The following describes the model constructs and related hypothesis.

\section{Service Quality (SVQ)}

There is still no published information on the purpose of measuring quality of services in the online distancelearning context (Shaik et al., 2006). Generally, service quality represents the quality of support services provided to end users. The service quality measurements include: Reliability, tangibles, responsiveness, assurance and empathy of the system (Kettinger and Lee, 1997; Al-Busaidi and Al-Shihi, 2010). In terms of online courses, common measures of service quality are responsiveness, reliability and empathy, with all having significant influence on student satisfaction (Roca et al., 2006). We believe that the better service provided to the students the higher satisfaction level. To test this assumption, the following hypothesis is proposed.

H1: Service quality is positively linked to user satisfaction

\section{Information Quality (InQ)}

In general, information quality has been associated with measurements such as: accuracy, currency, precision, output timeliness, conciseness, completeness, format, relevance and reliability (Bailey and Pearson, 1983). In the context of online learning, information quality represents the perceived output produced by LMS. Commonly used indicators including: Sufficiency, completeness, accuracy, timeliness, relevance, format, accessibility and understandability are utilized to predict information quality (Saba, 2012; Al-Busaidi and Al-Shihi, 2010). Literature studies on user satisfaction have claimed that InQ has significant impact on satisfaction of user (Delone and McLean, 2003; Seddon, 1997).

H2: Information quality is positively related to user satisfaction

\section{System Quality (SyQ)}

Researchers in Information Technology (IT) have commonly used measurements such as: Accessibility, language, timeliness, efficiency, flexibility and integration factors in order to predict system quality (Wixom and Todd, 2005). In online learning systems, such as LMS, system quality equates to a student's observation of a system's performance. This perception can be measured by some factors which are: Availability, usability, ease of learning, realization of user expectations and response time (Freeze et al., 2010). Previous researchers have indicated that system quality directly influences student satisfaction (Almarashdeh, 2016; Ramayah and Leeb, 2012).

H3: System quality is positively related to user satisfaction

\section{Perceived Ease of Use (PEU)}

The Technology Acceptance Model (TAM) proposed PEU, which is concerned with the expectation of user that utilizing a target system is effort-free (Davis et al., 1989; Almarashdeh and Alsmadi, 2016). Perceived Ease of Use refers to qualities such as: Being user friendly, ease of use and ease of learning (Wixom and Todd, 2005). According to Ba and Johansson (2008) study on user satisfaction, PEU has effect the overall user satisfaction (Almarashdeh et al., 2010b).

H4: PEU is positively linked to user satisfaction

\section{Perceived Usefulness (PU)}

Perceived usefulness is the expectation of users that utilizing the proposed system can increase her or his work performance (Davis et al., 1989). The usefulness and relevancy factors are the main measurements of the students' perception (Wixom and Todd, 2005). Several studies suggest that PU has an important influence on student satisfaction (Ong et al., 2009).

H5: PU is positively linked to user satisfaction

\section{User Satisfaction (SAT)}

SAT is the potential influence of the LMS and the total assessment of the experience of users when utilizing the LMS. It is defined by two different variables; one of which is expectation from LMS and the other one is confirmation of these expectations (Ozkan et al., 2008). The user satisfaction influences the benefit or the net outcomes of the LM (Saba, 2012; Almarashdeh et al., 2011b).

H6: User satisfaction is positively related to net benefit

\section{Net Benefit (NB)}

NB shows the balance of positive and negative effects upon a user. Therefore, NB can be measure by: Efficiency, job effectiveness, effects, as well as decision quality and error reduction. The net benefit, influenced by many factors, resulted from a number of studies which used user satisfaction as the main factor to predict system outcomes (Delone and McLean, 2003; Almarashdeh et al., 2010a; Lee-Post, 2009). 


\section{Data Collection}

The population and sample were recognized and then the study questionnaire was designed depending on the requirements of study and from literature reviews. The questionnaire has been lunched online in April 2017 for 2 weeks after the pre-testing phase, were the pilot data was collected and then analyzed, with findings showing that the instrument was reliable to use. Furthermore, the suggestions and comments of the participant were taken into consideration. Hence, two experts in the field reviewed and revised the questionnaire. The final questionnaire consisted of 33 questions related to the used measurements including: System quality (9 questions), information quality (6 questions), service quality (5 questions) (Almarashdeh et al., 2010a), PEU (3 questions), PU (3 questions) (Almarashdeh et al., 2011a), student satisfaction (3 questions) and net benefit (4 questions), with 3 questions representing the background of sample. The sample was composed of 425 distance learning students at four universities. The sample size satisfied the previous recommendations in response to the survey (Hair et al., 2006). A 5 point-Likert-scale, which is ranging from answers of strongly agree to strongly disagree, was used to measure the items in the questionnaire.

\section{Data Analysis}

The Statistical Package for the Social Sciences (SPSS) and Structural Equation Model (SEM) were used to analyze the data. The first step of analysis of data is the reliability testing. The reliability testing (coefficient alpha) range of 0.80 or 0.90 is an indication for a well-constructed scale (Sekaran, 2003). The conducted questionnaire reliability testing value is 0.971 , which is an indication that the scale is well-constructed. Figure 2 shows the values of each construct reliability testing result.

\section{Demographic Information}

The background information of the samples indicates that the majority of the students are aged between 20 to 40 years old. The majority of the students hold bachelor degrees $(52.9 \%)$ and $23.8 \%$ are diploma holders. The highest percentage of the students have used LMS for a period of 1 to 3 years $(34.8 \%$ ), while $30.1 \%$ have used the LMS for between 3 and 7 years. Figures 3, 4 and 5 represent the demographic information obtained.

\section{Descriptive Statistics}

In data analysis, the reason of using descriptive statistics is to use a simple summary instead of the large amount of data. Descriptive statistics refer to a way of transforming data into graphic and numerical procedure, it will provide easy and clear method for person who reads to understand and interpret (Podsakoff et al., 2003). Frequency distributions and descriptive statistics were utilized to provide total view and represent the properties of the data that was collected. Descriptive statistics comprising standard deviation and means were obtained for the scaled variables, as presented in Table 1.

Table 1: Descriptive statistics

\begin{tabular}{lll}
\hline Item & Mean & Std. deviation \\
\hline System Quality (SyQ) & 3.687 & 0.8731 \\
Information Quality (InQ) & 3.742 & 0.8261 \\
Service Quality (SVQ) & 3.727 & 0.8021 \\
Perceived Usefulness (PU) & 3.827 & 0.9036 \\
Perceived Ease Of Use (PEU) & 3.830 & 0.8590 \\
User Satisfaction (SAT) & 3.721 & 0.7957 \\
Net Benefit (NB) & 3.789 & 0.8473 \\
\hline
\end{tabular}



Fig. 2: Cronbach's alpha 


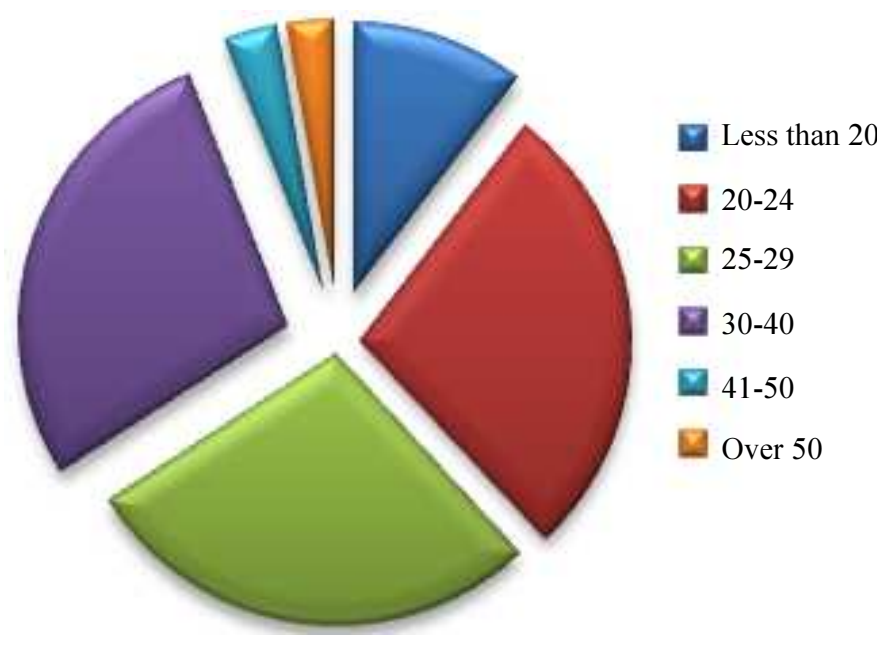

Fig. 3: Age
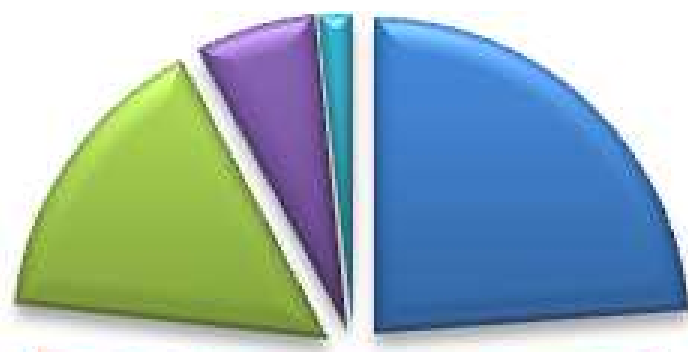

Diploma

Bachelor

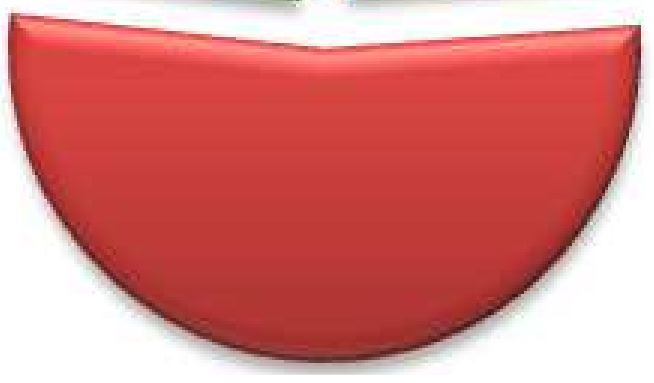

$\triangle$ Master

$\square \mathrm{PhD}$

Other

Fig. 4: Education level

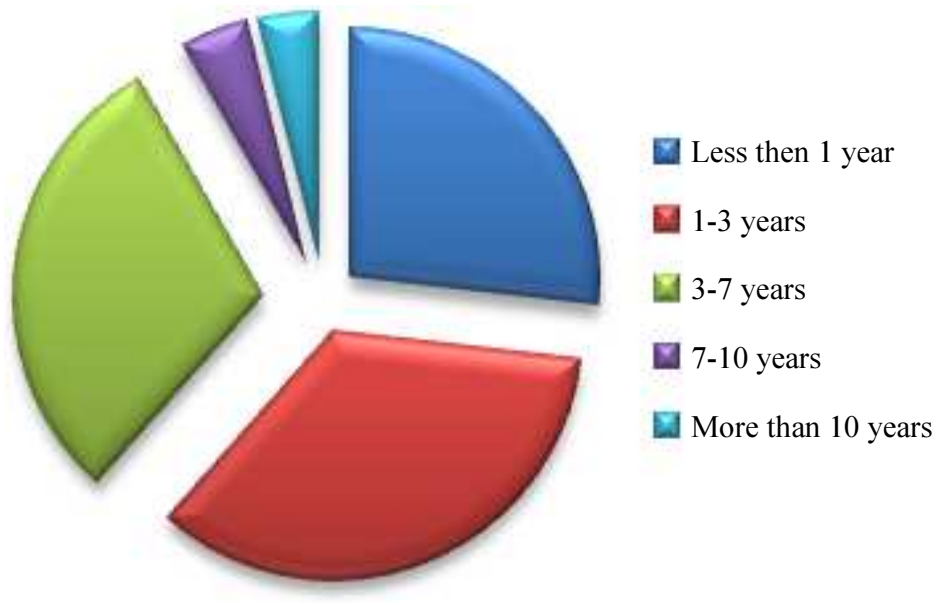

Fig. 5: LMS experience 
The result of descriptive statistics indicates that the mean is above 3.68 for all factors, with the respective means for all factors being the same. Therefore, the results were close around the mean, which indicates that opinions of students were similar. In this work, the values of standard deviations are between 0.79 and 1.00 , which means that there were small variations in the opinions of students.

\section{Measure of Fit}

The evaluation of model is the most challenging problem regarding SEM (Arbuckle, 2005). Before analyzing the structural model, it is important to first know how to evaluate it. The first step of building a structural model is achieved by using experimental knowledge and research of the theory to determine the association between the perceived variables and after that utilizing a statistical method to assess the theory. The CFA testing is affected by the requirements of: multivariate normality, enough sample size, measurement instruments, model fit indices interpretation, the tested research hypothesis, outliers, parameter identification, data that are missing (Schumacker and Lomax, 2004).

Since previous research studies suggested that minimum 10 participants for each free parameter should be estimated as the recommended number (Schreiber et al., 2006), this study used 23 parameters, with the sample size being 425 . The chi-square statistic $\left(x^{2}\right)$ is the most commonly described fit index in the field of structural equation modeling (Davey and Savla, 2009). The chisquare value determines how much is the data mismatched with the theories. Therefore, the CMIN connected with the higher probability value $(\mathrm{P})$, the nearer the fitting between the perfect fit and hypothesis (Byrne, 2009; Arbuckle, 2009). In the proposed model, the chi-square value is 11.017 and the P value 0.051, which indicates that the proposed model is right and does not differ from the other models. By measuring the total fit of the model, the results indicate that the Chi$\mathrm{sq} / \mathrm{df}$ is 2.203 at 5 degree of freedom (df), which shows that the model had a perfect fit. The User Satisfaction
Evaluation Model fit measures can be seen as summarized in Table 2.

The results in the Table 2 conclude the fit measures of the research model which indicate that the proposed model has a clear fit with the data. The advantages of fit measures illustrated in this study mostly obey the earlier research recommendations. The test results indicate that the hypothesis of the model is accepted and predicts the proposed model very well.

\section{Hypotheses Testing}

Figure 6 describes the standardized regression weights of the USEM hypothesis and the correlation between the independent variables as the SEM modification index recommended those variables to be correlated.

As shown in Fig. 6, all independent variables are associated with each other. The highest correlation is between PEU and PU (0.79), while the lowest is the correlation between PEU and SyQ (0.49). Furthermore, the figure represents the relationship between independent and dependent variables. All model hypotheses are accepted and show significance influence. Table 3 provides more details on the tested hypotheses.

In the proposed model, all of the pathways were significant. The C.R (critical ratio) illustrates the lowest C.R were between SAT and PEU with value of 2.089 for $\mathrm{H} 1$, with the highest being $\mathrm{H} 6$ between SAT and NB (12.3). The C.R indicates that the user satisfaction is more affected by system quality than the service quality.

Table 2: Fit measures summary

\begin{tabular}{lll}
\hline Fit Measures & Model Fit & Recommended value \\
\hline CMIN/Df & 2.203 & $<3$ \\
P Value & 0.051 & $>0.05$ \\
RMSEA & 0.053 & $<0.08$ \\
TLI & 0.988 & $>0.90$ \\
CFI & 0.997 & $>0.90$ \\
GFI & 0.993 & $>0.90$ \\
AGFI & 0.959 & $>0.90$ \\
RMR & 0.015 & $<05$ \\
IFI & 0.997 & $>0.90$ \\
RFI & 0.978 & $>0.90$ \\
NFI & 0.995 & $>0.90$ \\
\hline
\end{tabular}

Table 3: User Satisfaction Evaluation Model (USEM) hypotheses

\begin{tabular}{lllllll}
\hline No & Hypothesis & & & C.R & P & Result \\
\hline H1 & SAT & $<---$ & SVQ & 5.611 & $* * *$ & Support \\
H2 & SAT & $<---$ & InQ & 5.460 & $* * *$ & Support \\
H3 & SAT & $<---$ & SyQ & 6.684 & $* * *$ & Support \\
H4 & SAT & $<---$ & PEU & 2.098 & 0.036 & Support \\
H5 & SAT & $<---$ & PU & 5.746 & $* * *$ & Support \\
H6 & NB & $<---$ & SAT & 12.335 & $* * *$ & Support \\
\hline
\end{tabular}




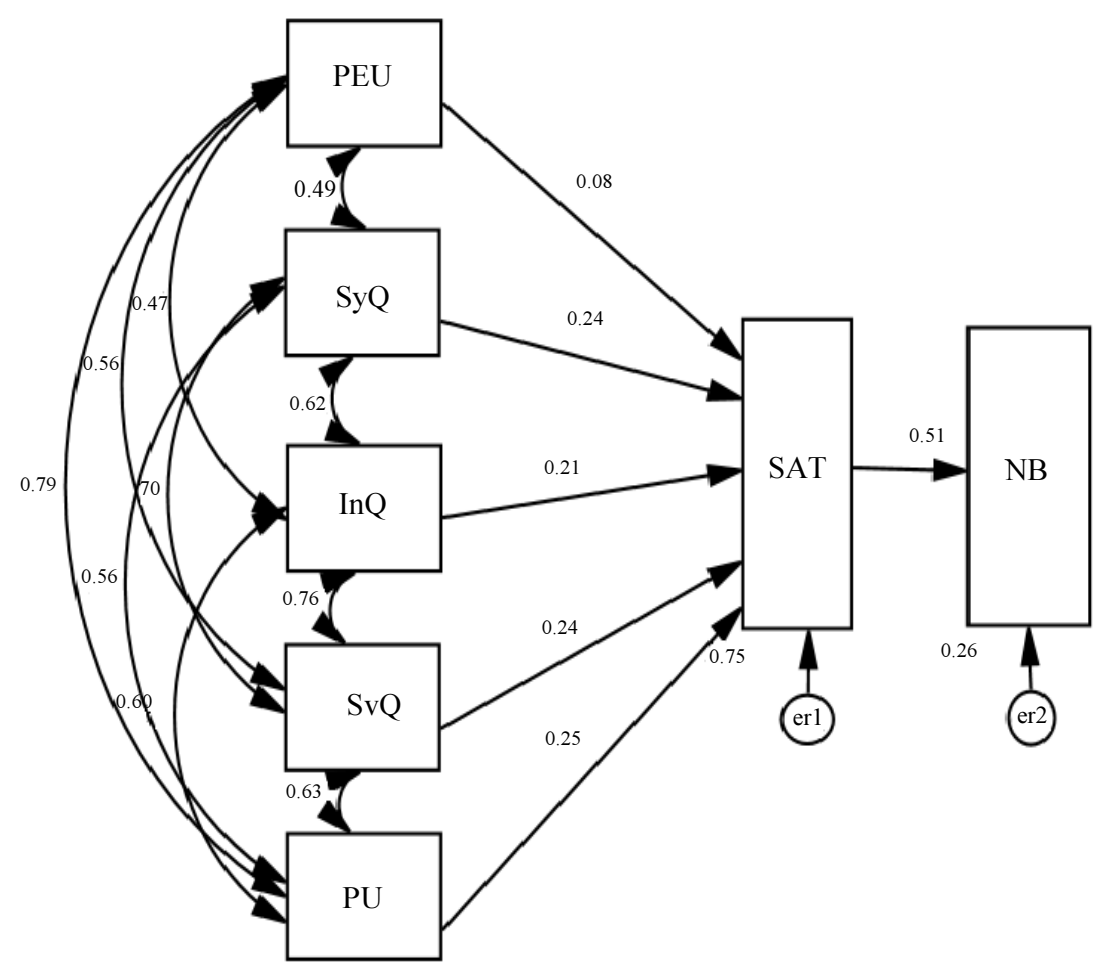

Fig. 6: Structural model

\section{Discussion}

Measuring the importance of factors contributing to the success of LMS in distance learning programs is the main concern of this study. The implications of the study indicated that there are strong significant influences among all independent and dependent variables. Using SEM to validate the USEM shows a valid result with CMIN/DF value 2.203, which indicates a very good fit (Byrne, 2009; Arbuckle, 2009). Hence, SEM has been used in this study for testing the hypothesis of the study using regression analysis. Based on the data analysis results, the highest impact on student satisfaction was system quality with value C.R 6.68 (indicating a strongly significant effect). This finding is consistent with blogbased learning systems success study of Yi-Shun et al. (2014).This indication represents the importance of: Availability, usability, ease of learning, realization of user expectations and response time factors (Freeze et al., 2010). These system quality factors represent the main predictor of student satisfaction.

Several studies suggest that Perceived usefulness has a major effect on student satisfaction (Ong et al., 2009). Perceived usefulness takes second place (C.R 5.74) in influencing student satisfaction. If the LMS is found to be useful, student satisfaction will increase. The third value affecting student satisfaction is based on service quality, which has a strong effect on student satisfaction (C.R 5.61). This implies that if the LMS provides good quality service (such as available support on a " $24 / 7$ " basis), useful services will be ready for students' use, as well as a high level of training and thus, student satisfaction will be increased (Hilmi et al., 2012). Furthermore, the information quality seems to have the same effect on student satisfaction as service quality. The result shows that information quality has a strong influence on student satisfaction (C.R 5.46). This indication confirmed that quality of information including: Relevance, accuracy, timeliness, completeness, sufficiency, understandability, accessibility and format (Saba, 2012; Al-Busaidi and Al-Shihi, 2010) are significantly important to the successful use of LMS in online courses. This, however, is not in line with the findings of a study by Green et al. (2012) who found that the delivery format has no significant influence on student satisfaction (Green et al., 2012).

Four hypotheses $(\mathrm{H} 1, \mathrm{H} 2, \mathrm{H} 3$ and $\mathrm{H} 4)$ have a similar value (C.R more than 5.4) in affecting students' satisfaction. However, H5 (which measures the influence of PEU on student satisfaction) is lowest among the others. The ease of use factor represents the simplicity of LMS and it has a significant effect on student satisfaction with C.R 2.09. This indication comes as a response from which previous researchers claim there is a need for understanding the PEU of LMS from the students' perception. However, the indication of the strong significant influence between PEU and student satisfaction is not in line with Adam (2000), who claims that PEU was not deemed to be among the 
most important factors affecting student satisfaction. Students will tend to use LMS more if it is easy to use and consequently will boost learning achievements (Hilmi et al., 2012).

User satisfaction plays an important role in predicting system outcomes (Delone and McLean, 2003; Lee-Post, 2009). Related studies suggest that student satisfaction influences the outcomes or the net benefit of using the LMS (Saba, 2012). By testing H6 (which represents the relationship between student satisfaction and net benefit), the results (C.R 12.3) indicate that student satisfaction has a very strong effect on the outcomes or net benefit acquired from using the LMS. This effect shows that the more students are satisfied with using LMS in their learning process, the greater the benefit that will be gained from that use. It is also anticipated that there would also be an increase in their proclivity.

As this implies, a lesser effort in using and understanding LMS affects student satisfaction, but not as LMS quality, which affects student satisfaction three times (C.R 6.68) more than the perceived ease of use (CR 2.09). Thus, universities should consider looking into the LMS quality, services quality and information quality more than the simplicity or the price of such system. The students satisfaction can be effected negatively if the LMS breakdown or if there is no support when they need it or no value of the available services or information the students. In general, the current LMS analysis considers the success dimensions as being related to: Information, service and system quality; usefulness and perceived ease of use; user satisfaction and net benefit. The factors of SYQ, INQ and SVQ, PU and PEU are considered to be factors that influence user satisfaction, which is the mediating factor for net benefit. The contribution of this work to the studies of user satisfaction is adoption of the most significant factors which have been seen to affect user satisfactions from past researches. Analyzing the research model by the SEM indicates that the relationships within the proposed model are assumed to measure the effect and cause within success factors, in addition to success measures. The User Satisfaction Evaluation Model is assumed to influence (negatively or positively) the LMS quality and so, to affect net benefit and user satisfaction.

The future research should consider using algorithms of artificial intelligent (AI) in LMS for scheduling and matching users with courses and materials (Nabiyev et al., 2013; Cavus, 2010; Wakelam et al., 2015; Sivakumar et al., 2015; Gomede et al., 2018). The AI nowadays used extensively in solving many difficult problems, such as river flow forecasting (Alsmadi, 2017a; Adeyemo et al., 2018), medical image analysis (Alsmadi, 2014; 2015; 2016a; Park and Han, 2018; Kermany et al., 2018), image segmentation (Farag et al., 2017; Thalji and Alsmadi,
2013; Alsmadi, 2016b; Badawi and Alsmadi, 2013; Sharma et al., 2018; Gao et al., 2018), Healthcare Monitoring (Almarashdeh et al., 2018; Rasmi et al., 2018), patterns recognition and information retrieval (Al Smadi et al., 2015; Alsmadi, 2016; Alsmadi and Omar, 2012; Alsmadi, 2017b; 2017c; Alsmadi et al., 2017; Badawi and Alsmadi, 2014; Yousuf et al., 2018) and nurse rostering problem (Jaradat et al., 2018).

As a direction for further research, this study was limited to students in distance learning courses; a larger sample size would have been better to validate the research model. Furthermore, as different users have different perceptions, measuring students' satisfaction in a different context might provide valid results. As the learning process is a complete sharing process between two players (instructors and students), future research in instructor satisfaction with using LMS might provide valuable results related to the success of distance learning courses. This research is limited to a few factors that affect student satisfaction. As to other factors (such as training and user experience of using LMS), we believe it might influence user satisfaction as a mediator between factors such as: Perceived usefulness, perceived ease of use, service quality, information quality, system quality and particularly, end user satisfaction in online learning.

\section{Conclusion}

This LMS evaluation is vital to ensure the positive impact and effective implementation on distance learning courses. Measuring the satisfaction of distance learners is very important for construction of a perfect distance learning platform for educational purposes. The USEM has been proposed based on a comparison between the IS success model and TAM, by choosing important factors related to user satisfaction in online courses. The USEM identified critical factors influencing the satisfaction of distance learners as: Five independent variables (information quality, service quality, perceived usefulness (and perceived ease of use), system quality as well as two dependent variables (net benefit and user satisfaction). In this research, a survey was carried out to obtain relevant data from distance learners related to their perceptions of the impact of the LMS in terms of their benefits and satisfaction level. The results indicate that all hypotheses are accepted, while the regression analysis shows the significant influence on user satisfaction by system quality, service quality, perceived usefulness, perceived ease of use and information quality. However, the strongest significant effect on students' satisfaction comes from system quality, while a lower significant effect comes from perceived ease of use. Based on these findings, it can be concluded while an LMS need not be too easy to use, but the LMS nevertheless needs to provide better services, high availability, usability, accessibility, better response time and providing useful features. As using LMS in 
universities becomes more and more widespread, the quality of LMS needs to be monitored. In the end, we hope future researches and developments can take into account lecturers' opinion when developing the LMS.

\section{Acknowledgement}

We are grateful to all participants whom shared their thoughts with us. This study did not have any financial support. All the work was done and all the expenses were paid for by the researcher.

\section{Author's Contributions}

Ibrahim Almarashdeh and Mutasem Khalil Alsmadi: Data collection, analysis, writing and editing.

Ghaith Jaradat and Ahmad Althunibat: Data collection and summarize the literature review.

Sami Abdullah Albahussain and Yousef Qawqzeh: Data analysis.

Usama A Badawi: Discuss the results.

Tamer Farag: Data collection.

Kamal Eldin Eldaw: Data analysis and discuss the results.

\section{Ethics}

This research manuscript is original and the manuscript is not published elsewhere. The corresponding author ensures that all authors have read and approved the manuscript and no ethical issues involved.

\section{References}

Adam, M., 2000. Variables affecting information technology end-user satisfaction: A meta-analysis of the empirical literature. Int. J. Human-Comput. Studies, 52: 751-771. DOI: 10.1006/ijhc.1999.0353

Adewumi, A.O., 2013. Deployment and usability evaluation of mobile access to institutional repository. MSc Thesis, Department of Computer and Information Sciences, Covenant University, Nigeria.

Al Smadi, A.M., M.K. Alsmadi, H. Al Bazar, S. Alrashed and B.S. Al Smadi, 2015. Accessing social network sites using work smartphone for face recognition and authentication. Res. J. Applied Sci., Eng. Technol., 11: 56-62. DOI: 10.19026/rjaset.11.1675

Al-Busaidi, K.A. and H. Al-Shihi, 2010. Instructors' Acceptance of learning management systems: A theoretical framework. IBIMA Publishing Commun., 1: 1-10. DOI: 10.5171/2010.862128

Almarashdeh, I. and M. Alsmadi, 2016. Investigating the acceptance of technology in distance learning program. Proceedings of the International Conference on Information Science and Communications Technologies, Nov. 2-4, IEEE Xplore Press, Tashkent, Uzbekistan, pp: 1-5. DOI: 10.1109/ICISCT.2016.7777404
Almarashdeh, I. and M.K. Alsmadi, 2017. How to make them use it? Citizens acceptance of m-government. Applied Comput. Informat., 13: 194-199.

Almarashdeh, I., 2016. Sharing instructors experience of learning management system: A technology perspective of user satisfaction in distance learning course. Comput. Human Behavior, 63: 249-255. DOI: $10.1016 /$ j.chb.2016.05.013

Almarashdeh, I., M.K. Alsmadi, T. Farag, A.S. Albahussain and U.A. Badawi et al., 2018. Real-time elderly healthcare monitoring expert system using wireless sensor network. Int. J. Applied Eng. Res., 13: 3517-3523.

Almarashdeh, I.A., N. Sahari, N.A.M. Zin and M. Alsmad, 2010a. The success of learning management system among distance learners in Malaysian Universitie. J. Theoretical Applied Inform. Technol., 21: 80-91.

Almarashdeh, I.A., N. Sahari, N.A.H.M. Zin and M. Alsmadi, 2010b. Distance learners acceptance of learning management system. Proceedings of the 2nd International Conference on Data Mining and Intelligent Information Technology Applications, (ITA'10), Seoul, Korea, pp: 304-309.

Almarashdeh, I., N. Sahari, N.M. Zin and M. Alsmadi, 2010c. Instructors acceptance of distance learning management system. Proceedings of the International Symposium on Information Technology, (SIT'10), Kuala Lumpur, pp: 1-6. DOI: 10.1109/ITSIM.2010.5561344

Almarashdeh, I., N.F. Elias, N. Sahari and N.A.M. Zain, 2013. Development of an interactive learning management system for malaysian distance learning institutions. Middle East J. Sci. Res., 14: 1471-1479. DOI: 10.5829/idosi.mejsr.2013.14.11.2339

Almarashdeh, I.A., N. Sahari, N.A.M. Zin and M. Alsmadi, 2011a. Acceptance of learning management system: A comparison between distance learners and instructors. Adv. Inform. Sci. Service Sci., 3: 1-9. DOI: 10.4156/aiss.vol3.issue5.1

Almarashdeh, I.A, N. Sahari, N.A.M Zin and M. Alsmadi, 2011b. Instructor's success measures of learning management system. Proceedings of the International Conference on Electrical Engineering and Informatics, (EEI'11), Bandung, Indonesia, pp: 1-7.

AlMaskari, A. and M. Sanderson, 2010. A review of factors influencing user satisfaction in information retrieval. J. Am. Society Inform. Sci. Technol., 61: 859-868. DOI: 10.1002/asi.21300

Alsmadi, M. and K. Omar, 2012. Fish Classification: Fish Classification Using Memetic Algorithms with Back Propagation Classifier. 1st Edn., LAP LAMBERT Academic Publishing.

Alsmadi, M.K., 2016a. A hybrid fuzzy c-means and neutrosophic for jaw lesions segmentation. Ain Shams Eng. J. DOI: 10.1016/j.asej.2016.03.016 
Alsmadi, M.K., 2016b. A hybrid fuzzy c-means and neutrosophic for jaw lesions segmentation. Ain Shams Eng. J. DOI: 10.1016/j.asej.2016.03.016

Alsmadi, M., 2016c. Facial recognition under expression variations. Int. Arab J. Inform. Technol., 13: 133-141.

Alsmadi, M., K. Omar and S.A.M. Noah, 2009a. Back propagation algorithm: The best algorithm among the multi-layer perceptron algorithm. Int. J. Comput. Sci. Netw. Security, 9: 378-383.

Alsmadi, M.K., K.B. Omar, S.A. Noah and I. Almarashdah, 2009b. Performance comparison of multi-layer perceptron (back propagation, delta rule and perceptron) algorithms in neural networks.Proceedings of the International Advance Computing Conference, Mar. 6-7, IEEE Xplore Press, Patiala, India, pp: 296-299.

DOI: 10.1109/IADCC.2009.4809024

Alsmadi, M.K., K.B. Omar and S.A. Noah, 2009c. Proposed method to decide the appropriate feature set for fish classification tasks using artificial neural network and decision tree. IJCSNS, 9: 297-301.

Alsmadi, M., K. Omar, S. Noah and I. Almarashdeh, 2011. A hybrid memetic algorithm with backpropagation classifier for fish classification based on robust features extraction from PLGF and shape measurements Inform. Technol. J., 10: 944-954. DOI: $10.3923 /$ itj.2011.944.954

Alsmadi, M.K., K.B. Omar, S.A. Noah and I. Almarashdeh, 2010a. Fish recognition based on robust features extraction from color texture measurements using back-propagation classifier. J. Theoritical Applied Inform. Technol., 18: 11-18.

Alsmadi, M., K.B. Omar, S.A. Noah and I. Almarashdeh, 2010b. Fish recognition based on robust features extraction from size and shape measurements using neural network. J. Comput. Sci., 6: 1088-1094.

Alsmadi, M.K., 2014. A hybrid firefly algorithm with fuzzy-C mean algorithm for MRI brain segmentation. Am. J. Applied Sci., 11: 1676-1691. DOI: $10.3844 /$ ajassp.2014.1676.1691

Alsmadi, M.K., 2015. MRI brain segmentation using a hybrid artificial bee colony algorithm with fuzzy-c mean algorithm. J. Applied Sci., 15: 100-109. DOI: $10.3923 /$ jas.2015.100.109

Alsmadi, M.K., 2017a. Forecasting River Flow in the USA using a hybrid metaheuristic algorithm with back-propagation algorithm. Sci. J. King Faisal Uni. (Basic Applied Sci.), 18: 13-24.

Alsmadi, M.K., 2017b. An efficient similarity measure for content based image retrieval using memetic algorithm. Egyptian J. Basic Applied Sci., 4: 112-122. DOI: 10.1016/j.ejbas.2017.02.004

Alsmadi, M.K., 2017c. Query-sensitive similarity measure for content-based image retrieval using meta-heuristic algorithm. J. King Saud Uni. Comput. Inform. Sci.
Alsmadi, M.K., A.Y. Hamed, U.A. Badawi, I. Almarashdeh and A. Salah et al., 2017. Face image recognition based on partial face matching using genetic algorithm. SUST J. Eng. Comput. Sci., 18: 51-61.

Arbuckle, J., 2005. Amos 6.0 User's Guide. 1st Edn., SPSS, Chicago, USA.

Arbuckle, J., 2009. Amos ${ }^{\mathrm{TM}} 18.0$ User's Guide. 1st Edn., SPSS, Chicago, USA.

Ba, S. and W.C. Johansson, 2008. An exploratory study of the impact of e-service process on online customer satisfaction. Product. Operat. Manage., 17: 107-119. DOI: 10.3401/poms.1070.0006

Badawi, U.A. and M.K. Alsmadi, 2014. A general fish classification methodology using meta-heuristic algorithm with back propagation classifier. J. Theoretical Applied Inform. Technol., 66: 803-812.

Badawi, U.A. and M.K.S. Alsmadi, 2013. A hybrid memetic algorithm (genetic algorithm and great deluge local search) with back-propagation classifier for fish recognition. Int. J. Comput. Sci. Issues, 10: 348-356.

Bailey, J.E. and S.W. Pearson, 1983. Development of a tool for measuring and analyzing computer user satisfaction. Manage. Sci., 29: 530-545. DOI: $10.1287 / \mathrm{mnsc} .29 .5 .530$

Bergersen, B., 2004. User satisfaction and influencing issues. Netw. Syst. Administration Res. Surveys, 1: 5-26.

Byrne, B.M., 2009. Structural Equation Modeling with AMOS: Basic Concepts, Applications and Programming. 17 Edn., Routledge Academic.

Cavus, N., 2010. The evaluation of Learning Management Systems using an artificial intelligence fuzzy logic algorithm. Adv. Eng. Softw., 41: 248254. DOI: 10.1016/j.advengsoft.2009.07.009

Chen, C.Y., R.E. Chang, M. C. Hung and M.H. Lin, 2009. Assessing the quality of a web-based learning system for nurses. J. Med. Syst., 33: 317-325. DOI: $10.1007 / \mathrm{s} 10916-008-9193-1$

CSU, 2005. Learning Management System (LMS) strategic review. California State University, Chico.

Cyert, R.M. and J.G. March, 1992. A Behavioral Theory of the Firm. 2nd Edn., Wiley-Blackwell, Cambridge, Mass., USA, ISBN-10: 0631174516, pp: 268.

Davey, A. and J. Savla, 2009. Statistical Power Analysis with Missing Data: A Structural Equation Modeling Approach. 1st Edn., Routledge, ISBN-10: 1135269319, pp: 384.

Davis, F., R. Bagozzi and P. Warshaw, 1989. User acceptance of computer technology: A comparison of two theoretical models. Manage. Sci., 35: 982-1003. DOI: $10.1287 / \mathrm{mnsc}$.35.8.982

DeLone, W. and E. McLean, 1992. Information systems success: the quest for the dependent variable. Inform. Syst. Res., 3: 60-95.

DOI: $10.1287 /$ isre. 3.1 .60 
Delone, W. and E. McLean, 2003. The DeLone and McLean model of information systems success: A ten-year update. J. Manage. Inform. Syst., 19: 9-30. DOI: $10.1080 / 07421222.2003 .11045748$

Farag, T.H., W.A. Hassan, H.A. Ayad, A. S. AlBahussain and U.A. Badawi et al., 2017. Extended absolute fuzzy connectedness segmentation algorithm utilizing region and boundary-based information. Arabian J. Sci. Eng., 42: 3573-3583. DOI: 10.1007/s13369-017-2577-0

Freeze, R.D., K.A. Alshare, P.L. Lane and H.J. Wen, 2010. Is success model in e-learning context based on students' perceptions. J. Inform. Syst. Educ., 21: 173-184.

Gao, Y., X. Li, M. Dong and H.P. Li, 2018. An enhanced artificial bee colony optimizer and its application to multi-level threshold image segmentation. J. Central South Uni., 25: 107-120. DOI: $10.1007 / \mathrm{s} 11771-018-3721-\mathrm{z}$

Gautreau, C., 2011. Motivational factors affecting the integration of a learning management system by faculty. J. Educators Online, 8: 1-25.

Gitman, L.J. and C. McDaniel, 2008. The Future of Business: The Essentials. 3 Edn., Cengage Learning, ISBN-10: 1111807191, pp: 528.

Gomede, E., F.H. Gaffo, G.U. Briganó, R.M. de Barros and L.D.S. Mendes, 2018. Application of computational intelligence to improve education in smart cities. Sensors, 18: 1-26.

DOI: $10.3390 / \mathrm{s} 18010267$

Green, L.S., F.A. Inan and B. Denton, 2012. Examination of factors impacting student satisfaction with a new learning management system. Turkish Online J. Distance Educ., 13: 13-13.

Hair, J., W. Black, B. Babin, R. Anderson and R. Tatham, 2006. Multivariate Data Analysis. 6th Edn., Prentice-Hall International, New Jersey, ISBN-10: 0132281392, pp: 899.

Hilmi, M.F., Y. Mustapha, H.M. Ali and S. Pawanchik, 2012. Service quality and ease-of-use of a learning management system portal: perceptions of distance learners. Proceedings of the 1st Taibah University International Conference on Computing and Information Technology, (CIT'12), Al-Madinah AlMunawwarah, KSA.

Ibrahim, D.Z. and A.D. Silong, 1997. Assuring quality learning support for teachers' distance education program. Proceedings of the 11th Annual Conference in Distance and Open Learning, (DOL'97), Kuala Lumpur, Malaysia.

Ives, B., M.H. Olson and J.J. Baroudi, 1983. The measurement of user information satisfaction. Commun. ACM, 26: 785-793.

Jaradat, G.M., A. Al-Badareen, M. Ayob, M. Al-Smadi and I. Al-Marashdeh et al., 2018. Hybrid elitist-ant system for nurse-rostering problem. J. King Saud Uni. Comput. Inform. Sci.
Kermany, D.S., M. Goldbaum, W. Cai, C.C. Valentim and H. Liang et al., 2018. Identifying medical diagnoses and treatable diseases by image-based deep learning. Cell, 172: 1122-1131.

Kettinger, W.J. and C.C. Lee, 1997. Pragmatic perspectives on the measurement of information systems service quality. MIS Quarterly, 21: 223-239. DOI: $10.2307 / 249421$

Khalid, N., A.Z.M. Sofi, K.A. Rahman, N.F.A. Rahman and S.Z. Mohid, 2015. The effect of instructors' quality and perception antecedents on students' behavior in e-learning. Proceedings of the International Conference on Information Technology and Society, Jun. 8-9, Kuala Lumpur, Malaysia, pp: 265-272.

Lee-Post, A., 2009. e-Learning success model: An information systems perspective. Electronic J. eLearn., 7: 61-70.

Li, H., L. Zhang, L. Zhang and J. Shen, 2010. A user satisfaction analysis approach for software evolution. Proceedings of the International Conference on Progress in Informatics and Computing, Dec. 10-12, IEEE Xplore Press, Shanghai, pp: 1093-1097.

DOI: 10.1109/PIC.2010.5687999

Llewellyn, D.C., 2011. University system of Georgia: Learning management system transition task. Force Final Report, University System of Georgia.

MOHE, 2006. Report: Committee to Study, Review and Make Recommendations Concerning the Development and Direction of Higher Education in Malaysia. In: Towards Excellence, MHEM (Ed.), Kuala Lumpur, Ministry of Higher Education in Malaysia, Malaysia.

Naaj, M.A., M. Nachouki and A. Ankit, 2012. Evaluating student satisfaction with blended learning in a gender-segregated environment. J. Inform. Technol. Educ.: Res., 11: 185-200. DOI: $10.28945 / 1692$

Nabiyev, V., H. Karal, S. Arslan, A.K. ERUMIT and C. Ayça, 2013. An artificial intelligence-based distance education system: Artimat. Turkish Online J. Distance Educ., vol. 14: 81-98.

Naveh, G., D. Tubin and N. Pliskin, 2010. Student LMS use and satisfaction in academic institutions: The organizational perspective. Internet Higher Educ., 13: 127-133. DOI: 10.1016/j.iheduc.2010.02.004

Naveh, G., D. Tubin and N. Pliskin, 2012. Student satisfaction with learning management systems: A lens of critical success factors. Technol. Pedagogy Educ., 21: 337-350. DOI: $10.1080 / 1475939 X .2012 .720413$

Ong, C., M. Day and W. Hsu, 2009. The measurement of user satisfaction with question answering systems. Inform. Manage., 46: 397-403.

DOI: $10.1016 /$ j.im.2009.07.004 
Ozkan, S., R. Koseler and N. Baykal, 2008. Evaluating learning management systems: Hexagonal ELearning Assessment Model (HELAM). Proceedings of the European and Mediterranean Conference on Information Systems, (CIS'08), Dubai, UAE.

Park, S.H. and K. Han, 2018. Methodologic guide for evaluating clinical performance and effect of artificial intelligence technology for medical diagnosis and prediction. Radiology, 286: 800-809 DOI: $10.1148 /$ radiol.2017171920

Podsakoff, P., S. MacKenzie, J. Lee and N. Podsakoff, 2003. Common method biases in behavioral research: A critical review of the literature and recommended remedies. J. Applied Psychol., 88: 879-903. DOI: $10.1037 / 0021-9010.88 .5 .879$.

Rafi, A., K. Samsudin and H.F. Hanafi, 2015. Differences in Perceived Benefit, Use and Learner Satisfaction between Open Source LMS and Proprietary LMS. In: E-Learning - Instructional Design, Organizational Strategy and Management, Gradinarova, B. (Ed.), InTech.

Rai, A., S. Lang and R. Welker, 2002. Assessing the validity of IS success models: An empirical test and theoretical analysis. Inform. Syst. Res., 13: 50-69. DOI: $10.1287 /$ isre. 13.1.50.96

Ramayah, T. and J.W.C. Leeb, 2012. System characteristics, satisfaction and e-learning usage: A Structural Equation Model (SEM). Turkish Online J. Educ. Technol., 11: 196-206

Rasmi, M., M.B. Alazzam, M.K. Alsmadi, I.A. Almarashdeh and R.A. Alkhasawneh et al., 2018. Healthcare professionals' acceptance electronic health records system: Critical literature review (Jordan case study). Int. J. Healthcare Manage. DOI: $10.1080 / 20479700.2017 .1420609$

Roca, J., C. Chiu and F. Martínez, 2006. Understanding e-learning continuance intention: An extension of the technology acceptance model. Int. J. HumanComput. Studies, 64: 683-696. DOI: $10.1016 / \mathrm{j}$. ijhcs.2006.01.003

Saba, T., 2012. Implications of E-learning systems and self-efficiency on students outcomes: A model approach. Human-Centric Comput. Inform. Sci., 2: 1-11. DOI: $10.1186 / 2192-1962-2-6$

Sabherwal, R., A. Jeyaraj and C. Chowa, 2006. Information system success: Individual and organizational determinants. Manage. Sci., 52: 1849-1864. DOI: /10.1287/mnsc. 1060.0583

Schreiber, J.B., A. Nora, F.K. Stage, E.A. Barlow and J. King, 2006. Reporting structural equation modeling and confirmatory factor analysis results: A review. J. Educ. Res., 99: 323-338.

DOI: $10.3200 /$ JOER.99.6.323-338
Schumacker, R. and R. Lomax, 2004. A Beginner's Guide to Structural Equation Modeling. 2nd Edn., Psychology Press, Lawrence Erlbaum, ISBN-10: 1135641919, pp: 304.

Seddon, P., 1997. A respecification and extension of the DeLone and McLean model of IS success. Inform. Syst. Res., 8: 240-253. DOI: 10.1287/isre.8.3.240

Sekaran, U., 2003. Research Methods for Business: A SkillBuilding Approach. 4 Edn., John Wiley \& Sons, Inc, New York, ISBN-10: 0471384488, pp: 450.

Shaik, N., S. Lowe and K. Pinegar, 2006. DL-sQUAL: A Multiple-Item Scale for Measuring Service Quality of Online Distance Learning Programs. Online J. Distance Learn. Administration, Uni. West Georgia, Distance Education Center.

Sharma, M., G. Purohit and S. Mukherjee, 2018. Information Retrieves from Brain MRI images for tumor detection using hybrid technique K-Means and Artificial Neural Network (KMANN). In: Networking Communication and Data Knowledge Engineering, Perez, G., K. Mishra, S. Tiwari and M. Trivedi (Eds.), Springer,

ISBN-10: 978-981-10-4599-8, pp: 145-157.

Sher, A., 2009. Assessing the relationship of studentinstructor and student-student interaction to student learning and satisfaction in web-based online learning environment. J. Interactive Online Learn., 8: 102-120.

Sivakumar, S., S. Venkataraman and C. Gombiro, 2015. A user-intelligent adaptive learning model for learning management system using data mining and artificial intelligence. Int. J. Innovat. Res. Sci. Technol., 1: 78-81.

Thalji, Z. and M. Alsmadi, 2013. Iris recognition using robust algorithm for eyelid, eyelash and shadow avoiding. World Applied Sci. J., 25: 858-865.

Wakelam, E., A. Jefferies, N. Davey and Y. Sun, 2015. The potential for using artificial intelligence techniques to improve e-Learning systems. Proceedings of the European Conference on eLearning, (CEL'15).

Wixom, B. and P. Todd, 2005. A theoretical integration of user satisfaction and technology acceptance. Inform. Syst. Res., 16: 85-102. DOI: $10.1287 /$ isre. 1050.0042

Yi-Shun, W., L. Hsien-Ta, L. Ci-Rong and W. Chian, 2014. A model for assessing blog-based learning systems success. Online Inform. Rev., 38: 969-990. DOI: 10.1108/OIR-04-2014-0097

Yousuf, M., Z. Mehmood, H.A. Habib, T. Mahmood and T. Saba et al., 2018. A novel technique based on visual words fusion analysis of sparse features for effective content-based image retrieval. Math. Problems Eng., 2018: 1-14. 